\title{
On-line automated evaluation of lipid nanoparticles transdermal permeation using Franz diffusion cell and low-pressure chromatography
}

\author{
Ana Catarina Alves ${ }^{\mathrm{a}}{ }^{\dagger}$, Inês I. Ramos ${ }^{\mathrm{a}}{ }^{\dagger}$, Cláudia Nunes ${ }^{\mathrm{a}}$, Luís M. Magalhães ${ }^{\mathrm{a}}$, Hana \\ Sklenářováb, Marcela A. Segundo ${ }^{\mathrm{a}}$, José L.F.C. Lima ${ }^{\mathrm{a}}$, Salette Reis ${ }^{\mathrm{a}}$ \\ ${ }^{a}$ UCIBIO, REQUIMTE, Departamento de Ciências Químicas, Faculdade de \\ Farmácia, Universidade do Porto, Rua de Jorge Viterbo Ferreira, 228, 4050-313 \\ Porto, Portugal \\ ${ }^{b}$ Department of Analytical Chemistry, Faculty of Pharmacy in Hradec Kralove, \\ Charles University in Prague, Czech Republic \\ *Corresponding author. \\ E-mail: msegundo@ff.up.pt \\ Tel: $+351220428676 /$ Fax: +35122609348
}

${ }^{\dagger}$ A.C. Alves and I.I. Ramos have equally contributed to this work.

(C) 2015. This manuscript version is made available under the Elsevier user license http://www.elsevier.com/open-access/userlicense/1.0/ 
A low-pressure liquid chromatography system for the on-line quantification of caffeine loaded into lipid nanoparticles that permeates pig skin was developed. The apparatus includes a Franz diffusion cell with computer-controlled sampling that allows collection of acceptor solution with automatic compensation for sample withdrawing, and a C-18 reversed-phase monolithic column integrated in a typical Flow Injection Analysis (FIA) set-up where separation between caffeine and other matrix elements is performed before spectrophotometric quantification at $273 \mathrm{~nm}$.

Several parameters regarding chromatographic analysis (propulsion element, column length, mobile phase composition, and flow rate) were studied along with the establishment of the sampling procedure. Under the selected conditions (monolithic column Chromolith ${ }^{\circledR}$ RP-18 15 mm x 4.6 mm i.d., acetonitrile:water 10:90 (v/v), flow rate $0.45 \mathrm{~mL} \mathrm{~min}^{-1}$ ) a detection limit of $4 \mu \mathrm{M}$ and $\mathrm{RSD}$ values for caffeine concentration $<2 \%$ were achieved. High recovery values were obtained when Hepes buffer incubated as acceptor solution in presence of pig skin for 8 hours was spiked with caffeine $(103 \pm 5 \%)$. The developed system also accounts for low organic solvent consumption, low operating costs, low generation of waste and high sample throughput $\left(24 \mathrm{~h}^{-1}\right)$. Due to the real time automated sampling and high throughput, transdermal permeation profiles of nanoformulations can be established within a time frame seldom observed by conventional techniques.

Keywords: Franz diffusion cell, automated sampling, monolithic column, lowpressure chromatography, nanoparticle permeation 


\section{Introduction}

Dynamic in vitro assays in pharmaceutical analysis such as permeation, release and dissolution tests have been employed with diverse aims towards quality control of pharmaceutical preparations. Particularly, assays based on Franz diffusion cell are currently used to study transdermal permeation of free drugs and nanoparticle carriers loaded with active compounds [1-7]. Real time monitoring of these dynamic processes can be of high relevance as it allows the establishment of more complete permeation profiles, providing reliable kinetic information that is necessary to predict pharmacological outcomes. Besides this, real time monitoring affords considerable flexibility because sampling frequency can be adapted to the kinetic profile observed. Nevertheless it requires automated sampling as a replacement for laborious and tedious manual procedures, aiming precise control of time events [8-12].

Automated flow methods meet this need with advantageous throughput in an affordable way. As a matter of fact, flow systems offer the possibility of combining an automated procedure for sample collection, which can be adapted to simultaneous testing of multiple samples [13] with an analysis apparatus providing real time monitoring of long-term processes associated to high sampling frequencies. In addition, this kind of systems foster sample consumption in the microliter range, introducing minimum disturbance to the volume of the acceptor medium, particularly when high sampling frequencies are involved [14]. Several flow systems using several detection techniques have been developed for pharmaceutical analysis aiming at the continuous monitoring of dynamic processes [15-19]. An automated system based on the Sequential Injection Analysis (SIA) technique coupled with the Franz cell to study release rates of indomethacin from gels has been implemented [20]. A similar device 
has been applied to in vitro release studies of salicylic acid from semisolid dosage forms [21]. Furthermore, a methodology for the simultaneous determination of lidocaine and prilocaine release rate from topical formulations using sequential injection chromatography coupled with Franz cell has been proposed [22].

Nevertheless, the application of automated methods to analyze complex matrices such as biological samples, culture media for microorganisms or multicomponent drug samples is often associated with matrix interferences that can affect data validity. Monolithic columns have been successfully used in the determination of analytes embedded in complex matrices namely biological ones since they present low susceptibility to blockage or back-pressure phenomena, reducing the need for sample pre-treatment (eg. clean-up) [23-27]. For this reason, monolithic columns are suitable to be coupled to low-pressure flow systems, enabling the separation of analytes from matrix components [26-30]. The combination of Flow Injection Analysis (FIA) setups with liquid chromatography using monolithic columns has been applied to determine compounds present in complex matrices such as human urine [31], cosmetic and health care formulations [32, 33] and food products [34]. Such associations afforded separation efficiency along with high throughput, manifold versatility and the use of simple low cost equipment.

In this context, the present work proposed a real-time automated method based on a low-pressure liquid chromatographic system for the assessment of caffeine-loaded lipid nanoparticles permeation through pig skin. Caffeine, commonly administered for cell lipolysis stimulation [35], is quantified in the acceptor fluid as model analyte. The strategy proposed here aims to overcome the drawbacks of batch-wise procedures related to sampling errors that arise from the introduction of air bubbles between the surrogate skin and the acceptor liquid, and interferences in the direct measurement of 
target compounds due to the presence of matrix. Moreover, the risk of decomposition or contamination of samples using off-line measurement is diminished. Finally, real time analysis upon sample collection is also targeted to obtain more information about kinetic profiles.

\section{Materials and Methods}

\subsection{Reagents and solutions}

All reagents used were of analytical grade with no further purification. Water from Arium water purification systems (resistivity $>18 \mathrm{M} \Omega \mathrm{cm}$, Sartorius, Goettingen, Germany) was used for the preparation of all solutions. LC grade acetonitrile obtained from Merck (Darmstadt, Germany) was employed for mobile phase preparation. Cetyl palmitate was kindly offered by Gattefossé (France) and polysorbate 60 (Tween 60) was obtained from Merck (Germany). Caffeine and Hepes buffer were purchased from Sigma-Aldrich (St. Louis, MO, USA). Working standard solutions of caffeine ranging from 6.0 to $650 \mu \mathrm{M}$ were prepared by rigorous dilution of the respective stock solution $(1 \mathrm{mM})$ in Hepes buffer $(100 \mathrm{mM}, \mathrm{pH} 7.4$ and $\mathrm{I}=0.1 \mathrm{M}$ adjusted with $\mathrm{NaCl})$ after accurate weighing and volume metering. All solutions were stored at room temperature. The mobile phase for separation of caffeine (acetonitrile: water 10:90 $(\mathrm{v} / \mathrm{v}))$ was degassed before application by means of ultrasound. Porcine ear skin was purchased from a local supermarket, butched to remove hair and subcutaneous fatty tissue and divided in pieces.

\subsection{Solid lipid nanoparticles (SLN) preparation}


Lipid nanoparticles (LN) were produced by ultrasonication method [36]. Briefly, the lipid phase containing cetyl palmitate (450 mg), surfactant (100 mg of polysorbate 60 ) and caffeine $(50 \mathrm{mg})$ was melted at approximately $5-10^{\circ} \mathrm{C}$ above the solid lipid melting point followed by dispersion in $4.4 \mathrm{~mL}$ of water heated at the same temperature. A hot pre-emulsion was formed by high speed stirring during 60 seconds at $12000 \mathrm{rpm}$ in an ultra-turrax (Janke \& Kunkel IKA-Labortechnick, Staufen, Germany) followed by 10 minutes of sonication (SONICS Vibra cell, Newtown, USA) operating at $70 \%$ amplitude intensity. The obtained hot oil-in-water nanoemulsion was cooled down to room temperature allowing the inner oil phase to solidify and forming solid lipid nanoparticles (SLN) dispersed in an aqueous phase.

\subsection{Apparatus}

The flow system for permeation assays (Fig. 1) comprises a sampling module, which is connected on-line to a low-pressure chromatographic system, where the separation between caffeine and other matrix compounds is performed along with the quantification of caffeine at $273 \mathrm{~nm}$. The sampling module included a computercontroled Gilson (Villiers-le-Bel, France) Minipuls 3 peristaltic pump equipped with PVC tubing (id $1.02 \mathrm{~mm}$ ) that collects sample from the Franz cell acceptor solution with automatic compensation for sample withdrawing. Control of the peristaltic pump was performed using a purpose build Quick Basic software. The sampling module was connected to the chromatographic manifold by a Rheodyne 5020 (Luton, Bedfordshire, UK) six-port rotary injection valve equipped with a $27 \mu \mathrm{L}$ loop. Mobile phase was propelled through the system by multi-syringe burette (Crison Instruments, Allela, Spain) equipped with a single syringe $(5 \mathrm{~mL})$. A $15 \mathrm{~mm}$ reversed-phase monolithic column composed by two Chromolith ${ }^{\circledR}$ RP-18e $4.6 \mathrm{~mm}$ i.d. columns (10 
and $5 \mathrm{~mm}$, connected to each other in this particular order). A post-column flowthrough cell (internal volume $8 \mu \mathrm{L}$, optical path $10 \mathrm{~mm}$ ) supported by $1 \mathrm{~cm}$ cuvette holder (Ocean Optics, Winter Park, USA) was illuminated by $600 \mu \mathrm{m}$ fiber optic cable connected to the light source (deuterium-halogen light source model DH-2000, Top Sensor Systems, Eerbeek, The Netherlands). Emerging radiation was collected by another $600 \mu \mathrm{m}$ fiber optic cable, connected to a USB4000-UV-Vis CCD spectrometer (Ocean Optics). Data acquisition was controlled by a personal computer running FIAlab software (FIAlab Instruments, Inc.), version 5.9.320. Peak area was calculated using the Origin 8.5.1 software.

The components of the set up were connected to each other by PTFE tubes $0.8 \mathrm{~mm}$ id (Omnifit, Cambridge, UK). The connections were made employing end-fittings and connectors Gilson (Villiers-le-Bel, France).

\subsection{Transdermal permeation studies}

Porcine skin is structurally close to that of humans [37] therefore, it is well suited to represent permeability through human skin [38]. On the day of analysis, the skin was placed in Franz diffusion cell (PermeGear, Hellertown, USA). This cell (Fig.1) consisted of donor and acceptor compartments between which porcine skin was placed. The exposed skin surface area was $0.64 \mathrm{~cm}^{2}$ and the receiver compartment contained $5 \mathrm{~mL}$. The acceptor compartment was filled with Hepes buffer (100 mM, $\mathrm{pH} 7.4, \mathrm{I}=0.01 \mathrm{M}$ ) and maintained at $37{ }^{\circ} \mathrm{C}$ by a water bath in order to ensure the temperature of $32{ }^{\circ} \mathrm{C}$ on the surface of the skin. The acceptor compartment also contained a magnetic bar, promoting stirring during the experiment. After cell assembly, $600 \mu \mathrm{L}$ of solid lipid nanoparticles (SLN) containing $0.01 \%(\mathrm{w} / \mathrm{w})$ of 
caffeine were placed in the donor compartment and the latter was covered with Parafilm $^{\circledR}$. For each analysis, $175 \mu \mathrm{L}$ of sample were withdrawn with simultaneous reposition of the same volume of Hepes buffer in the acceptor compartment, comprising the first step of the analytical cycle (Table S1). The peristaltic pump (PP) was therefore switched on and maintained at a constant flow rate for $15 \mathrm{~s}$, at $0.70 \mathrm{~mL}$ $\min ^{-1}$, filling the injection valve loop. PP was then switched off and syringe pump (SP) was triggered to propel mobile phase through the low-pressure LC system at 0.45 $\mathrm{mL} \min ^{-1}$ (step II). Sample was injected into LC column allowing caffeine separation from matrix components (step III), followed by spectrophotometric quantification (273 nm, retention time of $87 \mathrm{~s})$. Samples were collected at 5 min intervals within the first two hours of permeation. Every experiment was followed by a calibration with six caffeine standards. For studies regarding flow system conditions and recovery assays, surrogate matrix was prepared by placing the acceptor solution and pig skin in the Franz diffusion cell, and incubating during $8 \mathrm{~h}$ at $37{ }^{\circ} \mathrm{C}$. The acceptor medium was collected, frozen at $-20{ }^{\circ} \mathrm{C}$ and spiked with caffeine upon analysis.

The samples taken from the acceptor medium with simultaneous reposition with buffer causes decrease in caffeine concentration inside the acceptor compartment. For instance, the sampling procedure yields a theoretical dilution profile for the analyte contained in the acceptor compartment of the Franz diffusion cell that can be described by the following equation (1):

$$
C_{n, \text { theoretical }}=C_{n-1}-\left(C_{n-1} \times \frac{\text { sample volume }}{\text { acceptor volume }}\right)
$$

where $\mathrm{C}_{n \text {,theroretical }}$ represents the concentration of $n^{\text {th }}$ sample, containing a caffeine concentration for which the dilution from acceptor solution addition is accounted for. 
Thus, recalculation of the measured concentration to the undiluted values of caffeine was required by using equation (2):

$C_{n, \text { corrected }}=C_{n, \text { measured }}+\frac{\text { sample volume }}{\text { acceptor volume }} \times\left(C_{1}+C_{2}+\cdots+C_{n-1, \text { measured }}\right)$

where $C_{n}$ represents the concentration of $n^{\text {th }}$-sample.

\section{Results and discussion}

\subsection{Low-pressure chromatographic conditions}

\subsubsection{RP-18 monolithic column}

The assembly of the low-pressure chromatographic system began by choosing a monolithic column that allowed good separation between matrix interferences and caffeine in order to eliminate interferences upon its measurement. It should be as short as possible to minimize backpressure, allowing its operation with low-pressure pumps. For this reason, the influence of column length in peak separation was studied by coupling several columns with different lengths $(5,10,15$ and $25 \mathrm{~mm}$; i.d. $4.6 \mathrm{~mm})$ to the flow system. A low bore $(5 \mathrm{~mm}$; i.d 3.0) column was also tested. Solutions containing caffeine and acceptor solution that has been in contact with pig skin were therefore injected and separation profiles were obtained. Indeed, it was observed that the length of the monolithic column had great impact on caffeine separation from matrix interferences. The $25 \mathrm{~mm}$ column originated excessive backpressure making it impossible to perform assays. The low bore column did not provide any separation between caffeine and matrix components. Separation of caffeine from interferences 
was only achieved using the $15 \mathrm{~mm}$ column, which was selected for following experiments.

\subsubsection{Mobile phase composition and flow rate}

The influence of mobile phase composition and flow rate regarding separation quality and caffeine retention time was also evaluated. Aiming the selection of the flow rate, peak elution was evaluated within a range between 0.20 and $0.80 \mathrm{~mL} \mathrm{~min}^{-1}$, which was the maximum attainable flow rate. Flow rates above $0.80 \mathrm{~mL} \min ^{-1}$ led to overpressure inside the system, with connection bursting upon operation. Thus, the flow rate selected to proceed was $0.45 \mathrm{~mL} \mathrm{~min}^{-1}$ as it provided efficient peak separation without compromising sample throughput. After setting the flow rate to $0.45 \mathrm{~mL} \min ^{-1}$, several mixtures of $\mathrm{ACN}$ : water were tested $(2: 98,4: 96,6: 94,8: 92$, 10:90, 12:88, (v/v)). Fig. 2 shows the chromatograms obtained for 4 of these mixtures. Chromatographic separation parameters are presented in Table 1. Impairment in resolution between caffeine peak and matrix components was observed as the content of acetonitrile increases. Using $12 \%(\mathrm{v} / \mathrm{v})$ of $\mathrm{ACN}$, caffeine separation was not achieved. In opposition, if the content in acetonitrile decreased below $4 \%(\mathrm{v} / \mathrm{v})$, the peaks were significantly broaden leading to poor resolution and longer analysis time. Moreover, for acetonitrile below 4\% (v/v), column lifetime was also significantly decreased. In fact, high contents in acetonitrile improved column lifetime, avoiding C18 groups collapse. Therefore, column conditioning was performed by aspirating a solution of acetonitrile: water 90:10 (v/v) for $30 \mathrm{~min}$ at the end of each working day. This procedure was also carried out whenever the column promoted backpressure within the flow system or a decrease in resolution was observed. 
For the stated reasons, the mixture acetonitrile:water 10:90 (v/v) was selected as mobile phase since it provided the best balance for an effective peak resolution (1.68) and caffeine peak separation from sample matrix with a good column lifetime (still working after 180 determinations).

\subsubsection{Propulsion elements}

With respect to mobile phase propulsion, a low-pressure device was selected, aiming a low cost flow setup. Hence, the repeatability of the analytical signal and the robustness of peristaltic pump versus a low-pressure syringe pump (SP) were assessed by ten consecutive injections of caffeine standard solution $(100 \mu \mathrm{M})$. Retention time repeatibility for caffeine was also estimated using both pumps. Alongside, the generated effluent was collected for 10 min to evaluate flow rate stability. RSD values for caffeine peak area were $2.4 \%$ and $3.6 \%$ for the PP and SP, respectively. Despite the lower repeatability attained for peak area, retention time RSD value was lower for the SP $(0.9 \%)$ when compared to the PP $(1.8 \%)$. Unlike the peristaltic pump tubings, the SP material was adequate to handle organic solvents, such as acetonitrile, without compromising tubing lifetime. The SP provided constant flow rates throughout the whole experiment showing that the backpressure of the flow system never exceeded the maximum pressure tolerable by the propulsion system used (approx. 10 bar) proving the system compatible with low-pressure chromatography. For this reason, SP was selected for further experiments.

\subsection{Development of sampling procedure}


To ensure that the injection loop was completely filled with fresh acceptor solution from the Franz cell before each injection, several time intervals $(5,10,15,20,25 \mathrm{~s})$ for pump activation (and for sample collection) were studied along with the respective flow rates. Different combination of sampling flow rates (between 0.4 and $1.6 \mathrm{~mL}$ $\min ^{-1}$ ) and sampling time were tested and repeatability was calculated. The best balance time for loop filling/repeatability was achieved by collecting sample for $15 \mathrm{~s}$ before injection, at $0.60 \mathrm{~mL} \mathrm{~min}^{-1}$. Under these conditions, RSD value $(n=6)$ for the analytical signal provided by caffeine standard solution $(100 \mu \mathrm{M})$ was $2 \%$.

To evaluate the performance of the sampling procedure for successive collections of acceptor solution, the dilution profile obtained for sample collection throughout time of assay was established and compared to theoretical values. For that purpose, 440 $\mu \mathrm{M}$ of caffeine in Hepes buffer were placed inside the Franz cell, 29 sampling cycles were performed and the concentration profile obtained was plotted as a function of sampled volume (Fig. S1). As stated before, the theoretical curve was estimated according to the equation 1 .

As depicted in Fig. S1, the experimental curve was in good agreement with the theoretical curve, which means that the sampling module is suitable for application to permeation assays. In addition, it was estimated that only $52 \mu \mathrm{L}$ were lost after 12 sampling cycles, which represents $<1 \%$ of the total acceptor volume within the Franz cell. The present data indicates that the automatic withdrawing/reposition operation was successfully implemented, without formation of air bubbles close to the pig skin or bias sampling volume and concentration assessment.

\subsection{Analytical parameters and LC method validation}


Once sampling and LC conditions were selected, calibration curves were performed using standard solutions of caffeine and a linear correlation was established between peak area and caffeine concentration, defining two working ranges, between 6 and $200 \mu \mathrm{M}$ (low level) and between 100 and $650 \mu \mathrm{M}$ (high level). Calibration curves were repeated in three different days and each standard solution was analyzed in triplicate, providing parameters compiled in Table 2.

Detection limit was calculated applying the signal to noise ratio $(\mathrm{S} / \mathrm{N})$ method [39], after 10 consecutive blank injections, using Hepes buffer $(50 \mathrm{mM}, \mathrm{pH} 7.4)$ containing matrix residues and the value obtained was $4 \mu \mathrm{M}$.

Precision was estimated at both the low $(6 \mu \mathrm{M})$ and the high $(500 \mu \mathrm{M})$ levels of the calibration curve. Concerning intra-assay precision, 4 consecutive injections of the respective standard solution were carried out affording RSD values $<2 \%(6 \mu \mathrm{M})$ and $<1 \%(500 \mu \mathrm{M})$. As for inter-assay precision, RSD values found were $<15 \%$ and $<7$ $\%$ for the low and the high level, respectively [39].

To evaluate accuracy, recovery assays were performed using surrogate matrix. It was spiked with 6 or $500 \mu \mathrm{M}$ of caffeine and each solution was injected 4 consecutive times. Recovery values were $103 \pm 2 \%(6 \mu \mathrm{M})$ and $103 \pm 5 \%(500 \mu \mathrm{M})$. High recovery values indicate the absence of matrix effects, concerning both caffeine interaction with matrix compounds and complete separation of caffeine peak from matrix signal in the LC run.

Sample throughput was calculated by adding the time required to perform each step of a complete analytical cycle (Table S1), which was 145 s. Hence, estimated sample throughput was approximately $24 \mathrm{~h}^{-1}$. Concerning waste production, each cycle generated around $975 \mu \mathrm{L}$ of organic effluent waste with an estimated cost per analysis $<0.05$ euros. 


\subsection{Application to Franz cell permeation studies}

To validate the low-pressure LC system, permeation assays were carried out in three different days using the formulations of lipid nanoparticles loaded with caffeine. Permeation profiles were assessed within the first two hours of the process (Fig. 3). Since the mobile phase contains $\mathrm{ACN} 10 \%(\mathrm{v} / \mathrm{v})$, the nanoparticle matrix was destroyed, with consequent caffeine release, assuring that measured concentration corresponds to the total amount of drug that permeated the tissue during the assay. As it can be observed, the obtained curves are not overlapped once they correspond to the permeation profile of caffeine in different areas of pig ear skin, presenting differences in thickness. Future studies using this new tool will be conducted towards evaluating how reproducibility profiles can be affected by pig skin variability, besides variation in delivery formulation.

\section{Conclusions}

A low-pressure chromatographic system for the on-line quantification of caffeine that permeates pig skin was developed. The system includes a Franz diffusion cell apparatus with automated sampling and a low-pressure LC device based on a C-18 reversed-phase monolith.

The described strategy combines a fast sampling process in an automated way with the separation from acceptor matrix followed by quantification of the analyte. This format allows real time analysis of permeation processes since sample is analyzed as soon as it is collected. For this reason, the operator is able to stop sampling whenever 
required. Furthermore, real time sampling and high throughput are compatible with analysis within a time frame seldom observed by conventional techniques. Monitoring of caffeine permeation within the first minutes of contact with pig skin was indeed possible. Permeation profiles with more data points were obtained, which are relevant to pharmacokinetic studies and, consequently, to predict drug effects.

The sample volume required is low (microliter scale) when compared to conventional methods introducing minimal disturbance to the assay due to dilution effects in the acceptor solution. Short analytical cycles (145 s) allowed sample collection in small time intervals (approximately every $5 \mathrm{~min}$ ) giving the possibility of acquiring more data points per assay, and consequently more information about the transdermal permeation process. Due to its versatility, the conditions of the system can be adapted to other analytes (including mixtures), which turns it into an excellent device to solve separation issues regarding biological matrices. Finally, the use of low-pressure propulsion elements can also be an economic advantage when it comes to system application to the study of other dynamic processes such as permeation through other membranes or drug release. 


\section{Acknowledgements}

A.C. Alves, I.I. Ramos, C. Nunes and L.M. Magalhães thank FCT (Fundação para a Ciência e Tecnologia) and POPH (Programa Operacional Potencial Humano) for their fellowships (SFRH/BD/82443/2011, SFRH/BD/97540/2013 and SFRH/BPD/81963/2011, SFRH/BD/12539/2003). This work received financial support from the European Union (COMPETE) and National Funds (FCT) through project UID/Multi/04378/2013 and from EU FEDER funds under the framework of QREN (Project NORTE-07-0124-FEDER-000067 and NORTE-07-0162-FEDER000124). 


\section{References}

[1] F.F. Larese, F. D’Agostin, M. Crosera, G. Adami, N. Renzi, M. Bovenzi, G. Maina, Toxicology 255 (2009) 33-37.

[2] M. Schäfer-Korting, W. Mehnert, H.-C. Korting, Adv. Drug Deliv. Rev. 59 (2007) 427-443.

[3] S. Küchler, M. Abdel-Mottaleb, A. Lamprecht, M.R. Radowski, R. Haag, M. Schäfer-Korting, Int. J. Pharm. 377 (2009) 169-172.

[4] T. Şenyiğit, F. Sonvico, S. Barbieri, Ö. Özer, P. Santi, P. Colombo, J. Control. Release 142 (2010) 368-373.

[5] T.C. Beber, D.F. Andrade, B. Kann, M.C. Fontana, K. Coradini, M. Windbergs, R.C.R. Beck, Eur. J. Pharm. Biopharm. 88 (2014) 602-613.

[6] C.-H. Huang, H.-C. Sung, C.-Y. Hsiao, S. Hu, Y.-S. Ko, Lasers Med. Sci. 28 (2013) 807-814.

[7] I. Scognamiglio, D. De Stefano, V. Campani, L. Mayol, R. Carnuccio, G. Fabbrocini, F. Ayala, M.I. La Rotonda, G. De Rosa, Int. J. Pharm. 440 (2013) 179-187.

[8] P.R. Rege, V.D. Vilivalam, C.C. Collins, J. Pharm. Biomed. Anal. 17 (1998) 1225-1233.

[9] I.J. Bosman, A.L. Lawant, S.R. Avegaart, K. Ensing, R.A. de Zeeuw, J. Pharm. Biomed. Anal. 14 (1996) 1015-1023.

[10] M. Córdoba-Díaz, M. Nova, B. Elorza, D. Córdoba-Díaz, J.R. Chantres, M. Córdoba-Borrego, J. Control. Release 69 (2000) 357-367.

[11] C.A. Squier, M. Kremer, P.W. Wertz, J. Pharm. Sci. 86 (1997) 82-84.

[12] X. Du, C.A. Squier, M.J. Kremer, P.W. Wertz, J. Oral Pathol. Med. 29 (2000) 80-85.

[13] J. Klimundová, K. Mervartová, H. Sklenářová, P. Solich, M. Polášek, Anal. Chim. Acta 573-574 (2006) 366-370.

[14] Z.-L. Fang, Q. Fang, X.-Z. Liu, H.-W. Chen, C.-L. Liu, Trac-Trends Anal. Chem. 18 (1999) 261-271.

[15] H. Sklenářová, P. Pávek, D. Šatínský, P. Solich, R. Karlíček, F. Štaud, Z. Fendrich, Talanta 58 (2002) 1145-1149.

[16] X.-Z. Liu, S.-S. Liu, J.-F. Wu, Z.-L. Fang, Anal. Chim. Acta 392 (1999) 273281.

[17] Z. Legnerová, H. Sklenářová, P. Solich, Talanta 58 (2002) 1151-1155.

[18] Z. Legnerová, D. Šatínský, P. Solich, Anal. Chim. Acta 497 (2003) 165-174.

[19] Z. Legnerová, J. Huclová, R. Thun, P. Solich, J. Pharm. Biomed. Anal. 34 (2004) 115-121.

[20] P. Solich, H. Sklenářová, J. Huclová, D. Šatínský, U.F. Schaefer, Anal. Chim. Acta 499 (2003) 9-16.

[21] J. Klimundová, H. Sklenářová, U.F. Schaefer, P. Solich, J. Pharm. Biomed. Anal. 37 (2005) 893-898.

[22] J. Klimundová, D. Šatinský, H. Sklenářová, P. Solich, Talanta 69 (2006) 730735.

[23] K.K. Unger, R. Skudas, M.M. Schulte, J. Chromatogr. A 1184 (2008) 393415.

[24] K.C. Saunders, A. Ghanem, W. Boon Hon, E.F. Hilder, P.R. Haddad, Anal. Chim. Acta 652 (2009) 22-31.

[25] G. Guiochon, J. Chromatogr. A 1168 (2007) 101-168. 
[26] D. Šatínský, P. Solich, P. Chocholouš, R. Karlíček, Anal. Chim. Acta 499 (2003) 205-214.

[27] K. Cabrera, J. Sep. Sci. 27 (2004) 843-852.

[28] J.R. Santos, A.O.S.S. Rangel, Anal. Chim. Acta 715 (2012) 57-63.

[29] F.S. Kika, J. Chromatogr. Sci. 47 (2009) 648-655.

[30] P. Chocholouš, P. Solich, D. Šatínský, Anal. Chim. Acta 600 (2007) 129-135.

[31] J.L. Adcock, P.S. Francis, K.M. Agg, G.D. Marshall, N.W. Barnett, Anal. Chim. Acta 600 (2007) 136-141.

[32] J. Ballesta Claver, M.C. Valencia, L.F. Capitan-Vallvey, Talanta 79 (2009) 499-506.

[33] J. Ballesta-Claver, M.C. Valencia, L.F. Capitan-Vallvey, Luminescence 26 (2011) 44-53.

[34] J.F. Garcia Jimenez, M.C. Valencia, L.F. Capitan-Vallvey, J. Liq. Chromatogr. Relat. Technol. 32 (2009) 1152-1168.

[35] A.V. Rawlings, Int. J. Cosmet. Sci. 28 (2006) 175-190.

[36] M. Ricci, C. Puglia, F. Bonina, C. Di Giovanni, S. Giovagnoli, C. Rossi, J. Pharm. Sci. 94 (2005) 1149-1159.

[37] W. Meyer, R. Schwarz, K. Neurand, Curr. Probl. Dermatol. 7 (1978) 39-52.

[38] R. Neubert, W. Wohlrab, Acta Pharm. Techn. 36 (1990) 197-206.

[39] ICH guideline Q2(R1): Validation of Analytical Procedures: Text and Methodology 2005. 
Tables

Table 1. Caffeine peak parameters employing increasing percentages in acetonitrile.

n.a., non applicable

${ }^{a}$ Resolution was calculated comparing caffeine peak with matrix interferences that are not retained by the column (void volume $40 \mathrm{~s}$ ). 
Table 2. Analytical parameters for caffeine determination $(273 \mathrm{~nm})$.

\section{High level}

Working range $(\mu \mathrm{M})^{a}$

6.0- 200

$100-650$

Calibration curve slope ${ }^{a}$

$0.02764 \pm 0.0012$

$0.02408 \pm 0.0009$

Calibration curve intercept ${ }^{a}$

$0.1069 \pm 0.0442$

$0.9316 \pm 0.1102$

Correlation coefficient

Detection limit $(\mu \mathrm{M})$

Precision

Intra assay $(\%)^{b}$

Inter assay (\%)

Accuracy

Recovery $(\%)^{c}$

$103.1(6 \mu \mathrm{M})$

$102.9(500 \mu \mathrm{M})$

$\operatorname{RSD}(\%)^{c}$

1.8

5.3

${ }^{a}$ Calibration curves of area vs caffeine concentration. Standard solutions of caffeine were injected in triplicate in three different days ( $n=8$ for each calibration curve).

${ }^{b}$ Relative standard deviation (RSD) values were calculated for repeated standard injections $(n=4)$.

${ }^{c}$ Hepes buffer incubated as acceptor solution in presence of pig skin matrix for 8 hours spiked with caffeine. Values in parentheses indicate spike level $(n=4)$. 


\section{Figure captions}

Fig. 1. Automatic Franz diffusion cell apparatus coupled to low pressure chromatographic system. LN, lipid nanoparticles; MC, monolithic column; W, waste; $\mathrm{CCD}$, spectrometer; SP, syringe pump; PP, peristaltic pump; MP, mobile phase (acetonitrile:water, 10:90, v/v). MP flow rate was $0.45 \mathrm{~mL} \mathrm{~min}^{-1}$ and PP flow rate was $0.70 \mathrm{~mL} \mathrm{~min}{ }^{-1}$. Franz cell was placed on top a attiring plate and it had thermostatic control set at $37^{\circ} \mathrm{C}$ by using a water bath (not represented in the figure).

Fig. 2. Effect of mobile phase composition on peak separation and caffeine retention time (flow rate $0.45 \mathrm{~mL} \mathrm{~min}^{-1}$ ). Peak (a) corresponds to matrix interferences and peak (b) corresponds to caffeine.

Fig. 3. Caffeine permeation profile through pig skin within the first $2 \mathrm{~h}$ of the permeation assay. Experiments were performed in three different days, using different parts of pig ear skin. 


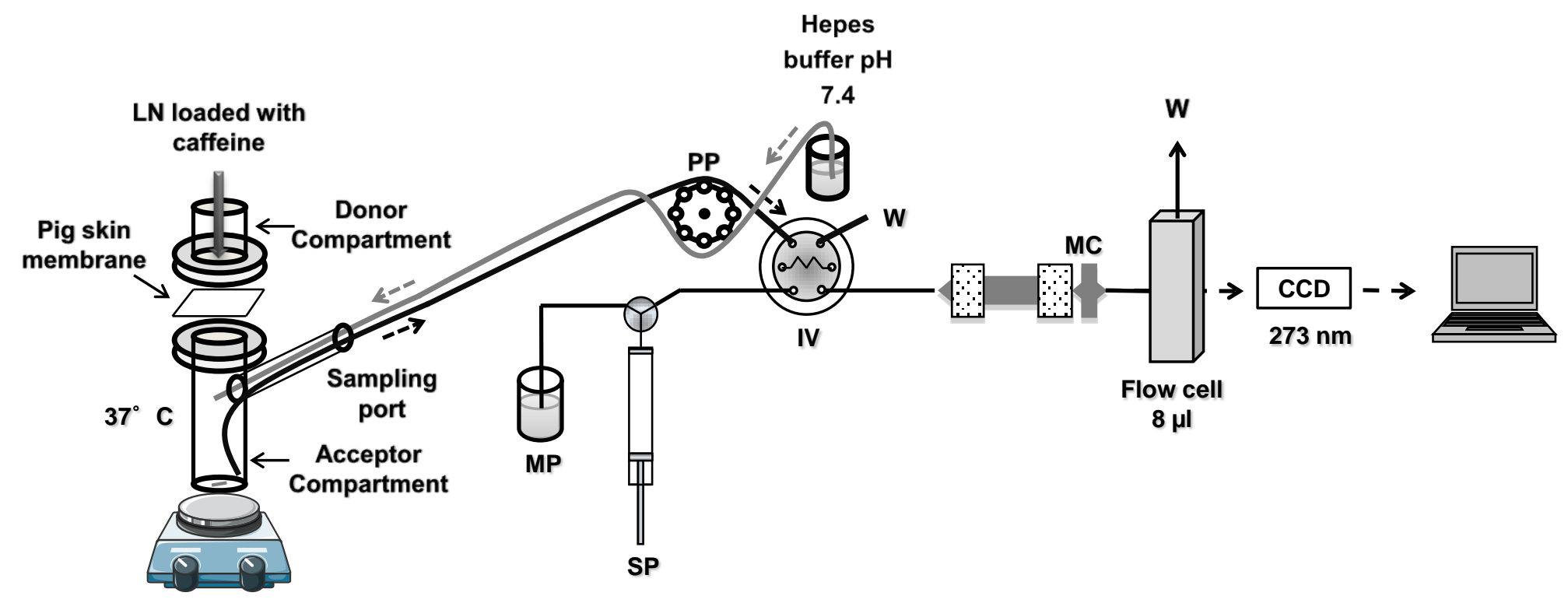

Fig. 1 


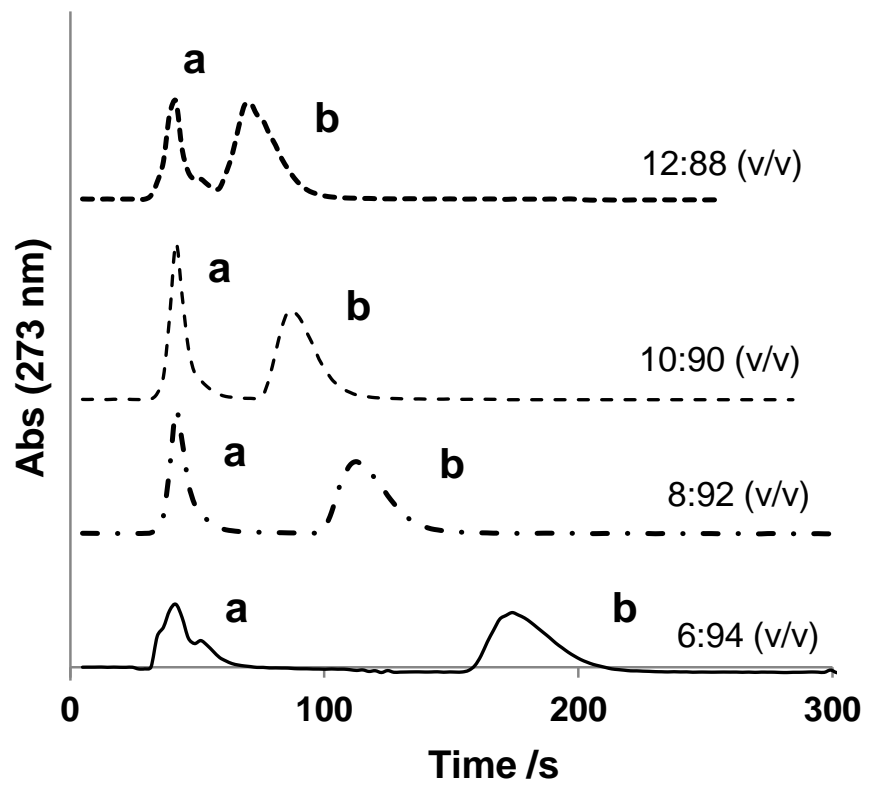

Fig. 2 


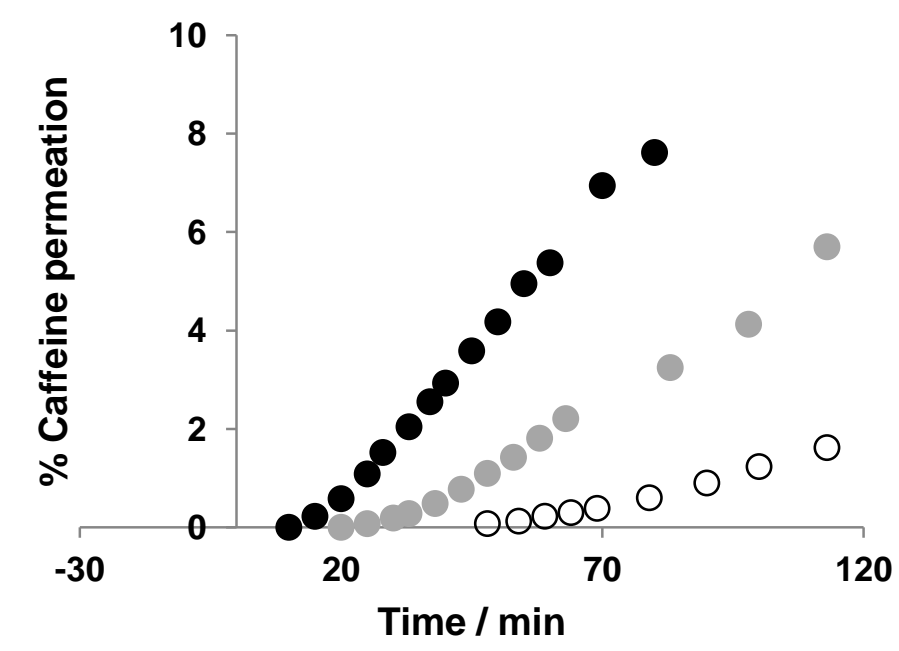

Fig. 3 


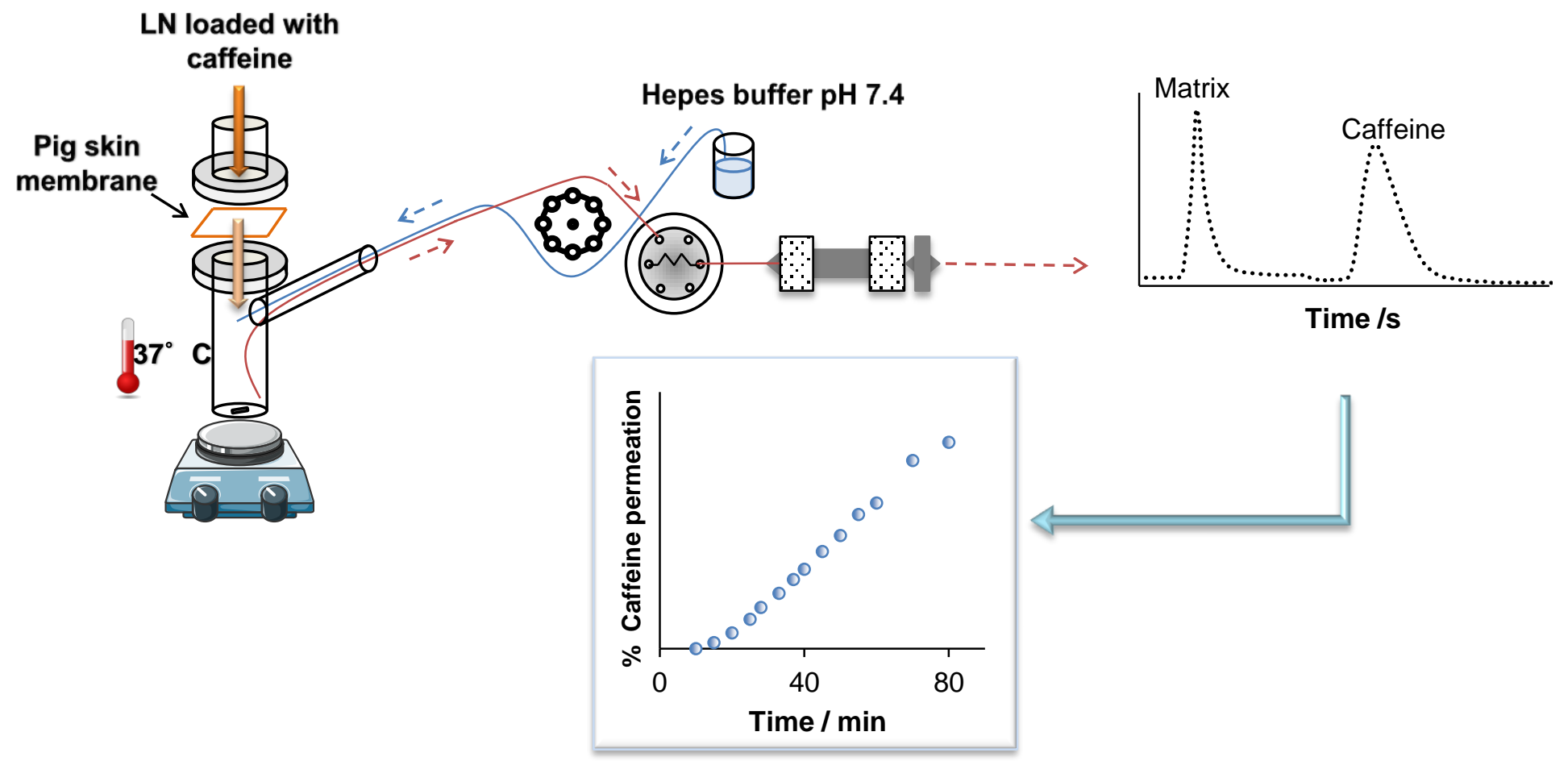

